\title{
CENSO DA ARBORIZAÇÃO URBANA DO MUNICÍPIO DE CAFEARA, PARANÁ
}

\author{
João Karlos Locastro', Giliane Gessica Rasbold², Janaina Silva Rossi Perreira ${ }^{3}$, \\ Bruna Soares ${ }^{4}$, Marcelo Galeazzi Caxambú ${ }^{5}$
}

\section{RESUMO}

A falta de planejamento adequado para a composição e estruturação da arborização urbana, acarreta inúmeros conflitos com os pedestres, equipamentos públicos e privados, que por sua vez elevam os custos com a manutenção destas áreas. Neste contexto é importante a realização de estudos que façam o levantamento da arborização municipal com a finalidade de pontuar as áreas com maior problemática, facilitando assim o planejamento e implantação de planos de manejo. Este trabalho teve como objetivo, realizar um censo da arborização urbana do município de Cafeara - PR, identificando os indivíduos que estavam em conflito com os equipamentos públicos. Foram identificados 1918 espécimes arbóreos, dos quais 183 apresentaram conflitos com o calçamento e 185 com a fiação elétrica. Observou-se ainda a presença de indivíduos em divergência com a legislação (27 indivíduos de Murraya paniculata). A espécie Ficus benjamina foi a que apresentou maior abundância, representando aproximadamente $27,5 \%$ da arborização municipal, sendo também a espécie com maiores conflitos com o calçamento e a fiação. De toda população arbórea analisada $19 \%$ dos indivíduos estão em conflito com o calçamento e $13 \%$ em conflitos com a fiação. Entretanto, o grau de conflitos pode ser ainda maior se o manejo das espécies arbóreas não for realizado de maneira adequada.

Palavras-chave: Calçamento; Fiação; Planejamento urbano.

\footnotetext{
Recebido em 21.05.2013 e aceito em 12.05.2015

1 Engenheiro Ambiental, Programa de Pós-Graduação em Engenharia Urbana, Universidade Estadual de Maringá, jklocastro@gmail.com.

2 Engenheira Ambiental, Programa de Pós-Graduação em Ecologia de Ambientes Aquáticos Continentais, Universidade Estadual de Maringá, grasbold@gmail.com.

3 Engenheira Ambiental, Universidade Tecnológica Federal do Paraná, câmpus Campo Mourão, j_janaina_a@hotmail.com. 4 Engenheira Ambiental, Universidade Tecnológica Federal do Paraná, câmpus Campo Mourão, bruuninhaaa_@hotmail.com. 5 Engenheiro Florestal, Professor da Universidade Tecnológica Federal do Paraná, câmpus Campo Mourão, mgcaxabu@yahoo.com.br
} 


\section{INVENTORY OF URBAN AFFORESTATION IN CAFEARA CITY, PARANÁ}

\section{ABSTRACT}

The lack of appropriate planning for the composition and organization of urban arborization entails numerous conflicts with pedestrians, public and private equipment, which in the turn increase the cost with the maintenance of these areas. In that context is important the realization of researches that made weighing of municipal arborization with purpose to point the most problematic areas, facilitating in this way the planning and implantation of adequate management plans. This work had as objective performing a census of the urban arborization of Cafeara city - PR, identifying the individuals that were conflicting with the public facilities. 1918 tree specimens were identified, of which 183 presented conflicts with the pavement and 185 with electrical wiring. There was also the presence of individuals in divergence with the law (27 individuals of Murraya paniculata). The species Ficus benjamina presented the greatest abundance, representing approximately $27.5 \%$ of the municipal arborization, also being the species with the greatest conflicts with the pavement and wiring. Of every tree population analyzed $19 \%$ of individuals are in conflict with the pavement and $13 \%$ in conflict with the wiring. However, the degree of conflict may be even higher if the management of tree species is not performed appropriately.

Keywords: Pavement; Wiring; Urban Planning.

\section{INTRODUÇÃO}

Em 2010, o Instituto Brasileiro de Geografia e Estatística (IBGE, 2010a) publicou dados de sua última pesquisa censitária, na qual aproximadamente $84 \%$ da população brasileira reside na zona urbana, com um crescimento de cerca de $3 \%$ em relação ao Censo de 2000. Segundo MEIRELLES (1977), este espaço urbano, onde vive a maioria dos brasileiros, caracteriza-se como um ambiente composto fundamentalmente de áreas edificadas, espaços de tráfego, e locais verdes (praça, quintais e parques), sendo estes últimos limitados, antes, por ruas estreitas, típicas do período colonial e atualmente pela 
presença de equipamentos públicos, fiação elétrica, redes de água e esgoto, além de elementos urbanos como: calçamentos, edificações, sinalização, tráfego, dentre outros.

Um dos modos de amenizar esse problema é a criação de um plano de arborização efetivo, que reduza os impactos causados pela grande aglomeração de pessoas. 0 planejamento da arborização é essencial para o desenvolvimento saudável da população e pode ser feito por meio da ampliação qualiquantitativa das áreas verdes urbanas existentes (MOURA e SANTOS, 2009). A absorção do gás carbônico, melhoria da qualidade do ar urbano, sombra, amenização de ruídos, proteção térmica, abrigo para animais e a sensação de bem estar são as principais funções da arborização urbana (MELLO FILHO, 1985; OLIVEIRA, 1996; BIONDI; ALTHAUS, 2005; GUZZO, 2008).

Apesar de todos os benefícios que a arborização urbana apresenta, há muitas dificuldades na sua implantação e permanência, tais como: impermeabilização do solo, vandalismo e produção de mudas de baixa qualidade (PREISSLER, 2011).

A arborização também pode ser uma fonte de transtorno para a comunidade, apesar de normalmente, isso ocorrer devido à implantação e manejos inadequados. Dentre alguns impactos negativos pode-se citar: a) danos às edificações com queda de galhos ou da árvore; b) disseminação de pragas (cupins e brocas); c) perda de atributos estéticos em função da deformação de suas copas pelas podas; d) aumento dos gastos, devido ao maior número de podas que são feitas para a desobstrução das fiações aéreas, haja vista a possibilidade de causar curtos circuitos e rompimento dos fios; e) aumento nos gastos com problemas de raízes, causando estragos em calçadas, redes de esgoto ou de água, interferências em bueiros; f) dificuldade de visualização de placas de orientação e do tráfego; g) restrição de passagem de pedestres (SEITZ, 1996; SANTOS; TEIXEIRA, 2001; SAMPAIO; DE ANGELIS, 2006; PIRES et al., 2007; MOSER et al., 2010).

Amir e Misgav (1990) citam três critérios que devem ser considerados no planejamento da arborização urbana: a) estabelecer as espécies que melhor se adaptam ao ambiente em termos paisagísticos; b) ponderar sobre as limitações físicas e biológicas que o ambiente aplica ao desenvolvimento dos espécimes; c) estimar quais espécies seriam mais apropriadas para melhorar o microclima e outras condições ambientais.

Para que não haja problemas com a arborização de passeios públicos, algumas características desejáveis nas espécies devem ser observadas: i) resistência a pragas e doenças; ii) velocidade de crescimento média ou rápida; iii) preferência por espécies nativas; iv) os troncos e ramos das árvores devem ser resistentes para evitar a queda na via pública, sendo ainda livres de espinhos e acúleos; v) ausência de princípios tóxicos e alérgicos; vi) beleza estética; vii) flores preferencialmente pequenas e de pouco odor; viii) 
frutos preferencialmente pequenos; ix) as folhas devem ter renovação e tamanhos favoráveis; $x$ ) a copa das árvores devem ter tamanho e forma adequadas, ou seja, não devem interferir me fiação, no trânsito de carros e pessoas e visualização de placas; xi) o sistema radicular deve ser profundo (PIVETTA; SILVA FILHO, 2002); xii) as espécies não devem ser exóticas invasoras (BIONDI; MACEDO, 2008).

Dentre outros critérios a serem observados na escolha das espécies, está a infraestrutura do local (limitação física), tamanho de ruas e passeios, presença de redes de atendimento público, arquitetura das construções e variabilidade nas espécies (mínimo de 15 espécies para a área de estudo) (PIVETTA; SILVA FILHO, 2002; ARAúJO; ARAúJO, 2011).

Para Araújo e Araújo (2011), a implantação de uma boa arborização urbana é baseada em um inventário arbóreo consistente dos logradouros da cidade. Os principais tipos de inventários são: parcial ou por amostragem, onde parte da população arbórea das ruas é avaliada e levantamento total ou censitário, quando toda a população é avaliada. Ainda de acordo com esses autores, um censo deve ser composto, minimamente dos seguintes dados: localização do espécime, identificação da espécie, diâmetro do tronco, altura da árvore, presença de pragas, necessidade de poda, largura da calçada, quantidade e tipo de tráfego, concordância com a presença de redes de serviço (luz, água, telefonia, esgoto, dentre outros), presença de marquises, distâncias de postes e esquinas.

Elencar as espécies inadequadas ao plantio ou permanência em áreas viárias é um fator decisivo em um plano de arborização urbana, pois espécies problemáticas podem causar danos físicos, monetários e sociais aos moradores e transeuntes. No entanto, a supressão geral da vegetação não é uma hipótese do plano de manejo da arborização de uma cidade, é necessário que o técnico responsável elabore planilhas de retirada, dando prioridade para as espécies que estejam demonstrando maior possibilidade de causar problemas aos cidadãos. Nesse caso, pode se citar riscos de queda, presença de espinhos ou acúleos, toxicidade.

Neste contexto, o presente estudo objetivou o levantamento censitário e a caracterização de espécies arbóreas em vias públicas do município de Cafeara - PR, a fim de analisar a abundância de espécies, verificar a existência de possíveis conflitos da arborização com equipamentos públicos presentes na urbe, além de atribuir o grau de importância de cada espécie na ocorrência dos devidos conflitos. 


\section{MATERIAIS E MÉTODOS}

\section{Área de estudo}

O trabalho foi realizado na cidade de Cafeara, situada no vale do Paranapanema, região norte do Estado do Paraná (Figura 1). O município conta com uma área total de 203,211 km² e uma população aproximada de 2486 habitantes de acordo com o Censo Demográfico do IBGE (2010b).

Tendo como base a classificação de Koppen (1931) a área de estudo apresenta clima Subtropical Úmido Mesotérmico (IAPAR, 2012), com predominância de verões quentes (temperatura média superior a $22^{\circ} \mathrm{C}$ ), invernos com geadas pouco freqüentes (temperatura média inferior a $18^{\circ} \mathrm{C}$ ) e sem uma estação seca definida.

A região caracteriza-se como uma área fitogeográfica de densa Floresta Tropical, classificada por Roderjan et al. (2002) como Floresta Estacional Semidecidual Submontana. O autor ressalta que neste ambiente são encontrados indivíduos arbóreos caducifólios, representando entre $20 \%$ e $50 \%$ do total de espécies.

Figura 1. Localização do Município de Cafeara, Paraná

Figure 1. Location of the Municipality of Cafeara, Paraná

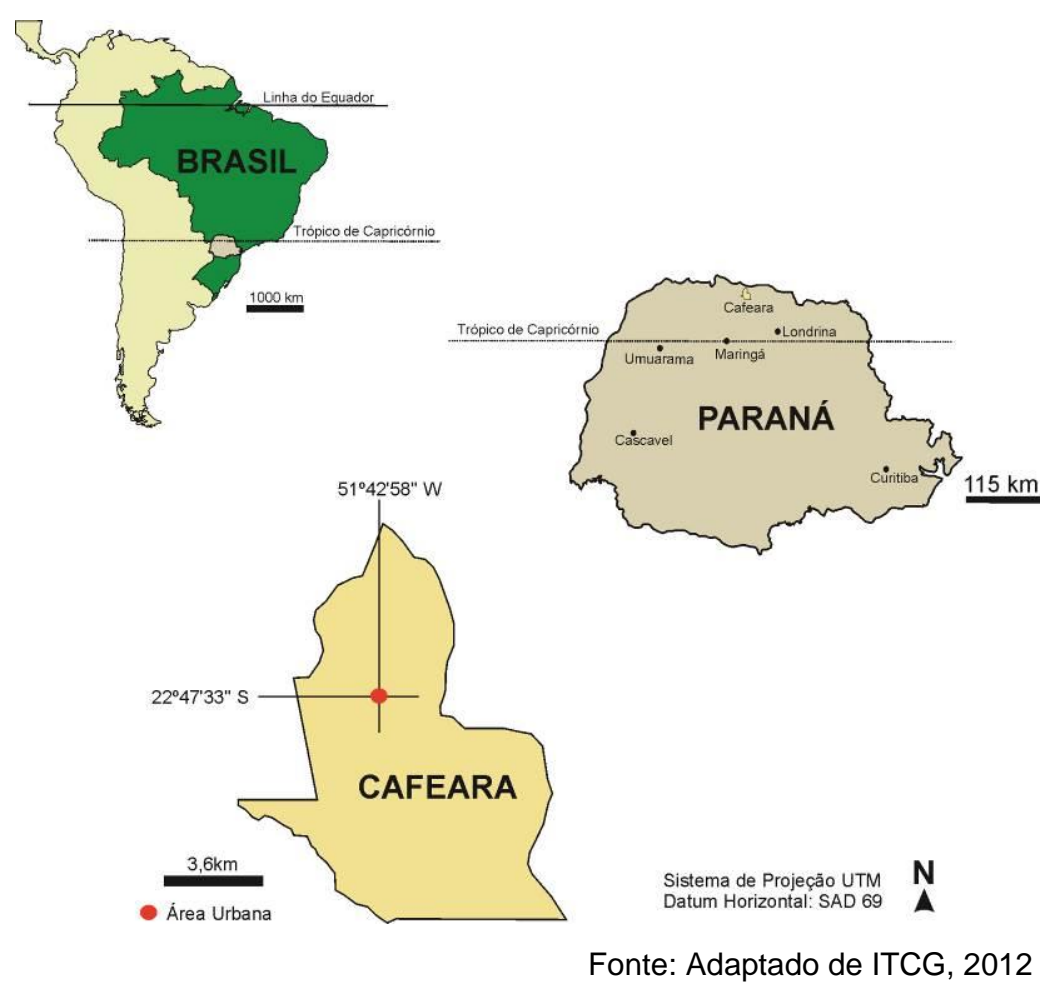




\section{Procedimentos metodológicos}

Para elaborar a relação de espécies arbóreas encontradas no Município de Cafeara, foram percorridas as 27 ruas existentes no perímetro urbano, identificando a nível específico todos os indivíduos existentes. Alguns indivíduos foram identificados com o auxílio de uma chave dicotômica no próprio local, os demais foram coletados de acordo com os procedimentos propostos em Fidalgo e Bononi (1989) e IBGE (2012), com a finalidade de facilitar a identificação nas dependências do Herbário da Universidade Tecnológica Federal do Paraná câmpus Campo Mourão - HCF. Para classificação foi utilizado o sistema de famílias a APG III (2009) e os epítetos específicos a Lista da Flora do Brasil (2013) e IPNI (2013).

O levantamento censitário foi executado analisando todos os espécimes vegetais existentes nas calçadas de passeio e canteiros centrais das vias públicas do município. $O$ estudo contou com a realização de observação in loco e registros fotográficos, identificando ainda possíveis conflitos das raízes e copas com o calçamento e a rede de fiação elétrica. Para determinar se um indivíduo arbóreo apresentava ou não conflitos com os equipamentos públicos seguiram-se a metodologia adaptada de Sampaio e De Angelis (2006) (Tabela 1).

Tabela 1. Critérios para o estabelecimento de conflitos com o calçamento e a fiação elétrica Tabela 1. Criteria for the establishment of conflicts with pavement and electrical wiring

\begin{tabular}{c|c|c}
\hline $\begin{array}{c}\text { Conflito Ausente } \\
\text { (Conflict Away) }\end{array}$ & Calçamento (Paving) & Fiação elétrica (Electrical Wiring) \\
\hline $\begin{array}{c}\text { Conflito Presente } \\
\text { (Existing Conflict) }\end{array}$ & $\begin{array}{c}\text { Raízes expostas (acima do nível do } \\
\text { solo), causando rachaduras, } \\
\text { levantamento de calçamento e } \\
\text { obstrução da passagem de pedestres. }\end{array}$ & $\begin{array}{c}\text { Interferência dos galhos na fiação } \\
\text { elétrica }\end{array}$ \\
\hline
\end{tabular}

Dessa forma, foi conduzida a elaboração de um croqui da área de estudo, a fim de identificar as principais espécies em conflitos com os bens públicos, bem como os locais de ocorrência de maiores problemas. Para realização do croqui anotou-se pontualmente em fichas de campo o local de ocorrência de cada espécime arbóreo [nome do logradouro, número da quadra, número da residência mais próxima e lado de disposição na rua (esquerdo ou direito), o tipo de conflito existente e a espécie conflitante.

Após o levantamento de todos os espécimes vegetais existentes foi elaborada uma tabela, classificando os espécimes quanto sua natureza (nativa ou exótica), sua abundância, e sua porcentagem de conflitos com o calçamento e a fiação. Para calcular a porcentagem 
de conflitos e abundância, foram utilizados índices adaptados de May (1975). Utilizando esses índices e mais as observações feitas durante o levantamento, foi adaptada a metodologia de WBCSD (2008) a fim de verificar quais espécies apresentaram maiores interferências no meio urbano. Para tanto, analisou-se a relação entre os conflitos existentes e a abundância das espécies registradas (QUADRO 1).

O índice de abundância expressa a relação entre o número de indivíduos de uma determinada espécie e o número de indivíduos de todas as espécies encontradas (Equação1).

$$
A_{B}=\frac{N_{A}}{N_{A}+N_{B}+N_{C}+\ldots \ldots . N_{N}} x 100
$$

onde:

$A_{B}=$ Abundância da espécie $A$.

$N_{A}, N_{B}, N_{C}, \ldots . . N_{N}=$ número total de indivíduos de espécie $A, B, C \ldots . . . N$.

O índice de conflitos com o calçamento (Equação 2) expressa a relação entre o número de indivíduos de uma determinada espécie que está em conflito com o calçamento e o número total de indivíduos de sua espécie.

$$
C c=\frac{Q c}{N_{A}} \times 100
$$

onde:

$\mathrm{C}_{c}=$ porcentagem de indivíduos da espécie A em conflito com o calçamento .

$Q_{c}=$ quantidade de indivíduos da espécie $A$ em conflito com o calçamento.

$\mathrm{N}_{\mathrm{A}}=$ número total de indivíduos de espécie $\mathrm{A}$.

O índice de conflitos com a fiação elétrica (Equação 3) expressa a relação entre o número de indivíduos de uma determinada espécie que está em conflito fiação e o número total de indivíduos de sua espécie.

onde:

$$
C_{F}=\frac{Q_{F}}{N_{A}} \times 100
$$

Eq.

$\mathrm{C}_{\mathrm{F}}=$ porcentagem de indivíduos da espécie $\mathrm{A}$ em conflito com a fiação.

$\mathrm{Q}_{\mathrm{F}}=$ quantidade de indivíduos da espécie $\mathrm{A}$ em conflito com a fiação.

$\mathrm{N}_{\mathrm{A}}=$ número total de indivíduos de espécie $\mathrm{A}$. 
Utilizando-se dos índices propostos foi organizada uma escala de magnitude para controle da arborização existente, classificando as espécies entre aquelas que precisam de maior monitoramento ou controle no meio urbano e aquelas que não carecem do mesmo por apresentarem baixa percentagem de espécimes em conflitos com equipamentos da urbe (calçamento ou fiação) e/ou por serem pouco abundantes na área de estudo.

Quadro 2. Relação entre abundância de espécies e conflitos da arborização com o calçamento e a fiação elétrica. Em que (1) representa espécies cujos problemas causados a urbe são irrelevantes; (2) refere-se a espécies que devem ser monitorada; (3) são espécies que devem ser controladas; (4) representam espécies que necessitam ser imediatamente controlada

Quadro 2. Relationship between abundance of species and conflicts of arborization with the pavement and electrical wiring. Where (1) are species whose problems caused the cities are irrelevant; (2) refers to species which are to be monitored; (3) are species that must be controlled; (4) represent species that need to be controlled immediately

\begin{tabular}{|c|c|c|c|c|c|c|c|c|c|}
\hline & \multicolumn{4}{|c|}{$\begin{array}{l}\text { Indivíduos em conflito com o } \\
\text { calçamento } \\
\text { (Individuals in conflict with the } \\
\text { pavement) }\end{array}$} & \multicolumn{4}{|c|}{$\begin{array}{l}\text { Indivíduos em conflito com a fiação } \\
\text { (Individuals in conflict with the } \\
\text { wiring) }\end{array}$} \\
\hline & & $\begin{array}{c}(0-5 \%) \\
\text { Baixa }\end{array}$ & $\begin{array}{l}(5-10 \%) \\
\text { Médio }\end{array}$ & $\begin{array}{l}(10-20 \%) \\
\text { Alta }\end{array}$ & $\begin{array}{c}(>20 \%) \\
\text { Muito Alta }\end{array}$ & $\begin{array}{c}(0-5 \%) \\
\text { Baixa }\end{array}$ & $\begin{array}{c}\text { (5-10\%) } \\
\text { Médio }\end{array}$ & $\begin{array}{c}(10-20 \%) \\
\text { Alta }\end{array}$ & $\begin{array}{l}(>20 \%) \\
\text { Muito } \\
\text { Alta }\end{array}$ \\
\hline \multirow{4}{*}{ 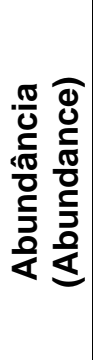 } & $\begin{array}{c}(0-5 \%) \\
\text { Baixa }\end{array}$ & 1 & 2 & 2 & 3 & 1 & 2 & 2 & 3 \\
\hline & $\begin{array}{c}\text { (5-10\%) } \\
\text { Médio }\end{array}$ & 2 & 2 & 3 & 3 & 2 & 2 & 3 & 3 \\
\hline & $\begin{array}{c}(10-20 \%) \\
\text { Alta }\end{array}$ & 2 & 3 & 3 & 4 & 2 & 3 & 3 & 4 \\
\hline & $\begin{array}{l}(>20 \%) \\
\text { Muito } \\
\text { Alta }\end{array}$ & 3 & 3 & 4 & 4 & 3 & 3 & 4 & 4 \\
\hline
\end{tabular}

Fonte: Adaptado de WBCSD (2008).

\section{RESULTADOS E DISCUSSÃO}

O município de Cafeara tem em sua arborização 1918 espécimes arbóreos, representados por 53 espécies, distribuídos em 30 famílias botânicas distintas. Entretanto, $53 \%$ da arborização é composta somente por três espécies vegetais, Ficus benjamina L. (Ficus) 27,5\%, Licania tomentosa (Benth.) Fritsch (Oiti) 13,2\% e Pachira aquatica Aublet (Munguba) 12,3\% (Tabela 2). A quantidade de $F$. benjamina, ultrapassa o valor recomendável de indivíduos da mesma espécie (10-15\%), pois em ruas com plantios homogêneos, as árvores correm o risco de se tornarem alvo fácil de pragas e doenças, o 
que acarreta perdas para o meio urbano (MILANO; DALCIN, 2000; BIONDI; ALTHAUS, 2005).

Das 53 espécies arbóreas e arbustivas encontradas em Cafeara, 17 são nativas, originárias do Brasil e 36 são exóticas (Tabela 2), ou seja, foram introduzidas no ecossistema natural (ZILLER, 2004). A predominância de espécies exóticas na composição da arborização verificada no município, não é uma exclusividade apenas da área de estudo, outros locais como, por exemplo, Chapadão do Sul (MS), Santa Maria (RS) e Senador Guiomard ( $A C)$ apresentaram também maior abundância de espécies exóticas, comprovada pela prática de inventários (ANDREATTA et al., 2011; MARANHÃO et al., 2012; PELEGRIM et al., 2012). De acordo com Paiva (2009), esta situação é regra geral na maioria das cidades brasileiras.

A arborização do município apresentou conflitos aparentes com os equipamentos públicos em $20 \%$ da sua arborização. Além disto, observou-se a presença de 27 indivíduos $(1,41 \%)$ de Murraya paniculata (L.) Jack., o que diverge com a legislação vigente. A espécie foi proibida para o estado do Paraná pela Lei Estadual 15.953/08 Secretaria de Estado de Agricultura e do Abastecimento do Estado do Paraná (PARANÁ, 2008), por serem plantas hospedeiras da bactéria Candidatus liberibacter ssp., disseminada pelo inseto vetor Diaphorina citri, transmissor da praga denominada Huanglongbing (HLB - Greening), doença considerada uma ameaça potencial a citricultura paranaense, sendo, portanto, recomendado a retirada dessa espécie da arborização do município.

Dos conflitos aparentes encontrados nos calçamentos e fiação elétrica da cidade, nota-se que a problemática é evidente principalmente em 3 espécies, sendo estas: $P$. pluviosa, responsável por $20,22 \%$ dos conflitos juntos ao calçamento e $17,44 \%$ à fiação, $P$. aquatica representando $21,31 \%$ dos conflitos com o calçamento e $27,18 \mathrm{com}$ a fiação e $F$. benjamina que apresentou $55,2 \%$ para a fiação e 34,87 para o calçamento.

Lorenzi et. al (2003) relata que a espécie $F$. benjamina é inconveniente para a arborização de ruas e avenidas, devido seu excessivo vigor de sistema radicular. Santos e Teixeira (2001) evidenciam que árvores do gênero Ficus spp. não são recomendadas, pois apresentam porte avantajado, sistema radicular superficial e agressivo, comprometendo pisos e paredes, além de folhagem dura responsável pelo entupimento de calhas, bueiros e bocas de lodo.

Devido às características de F. benjamina, observou-se que apenas $19 \%$ dos espécimes encontrados na arborização de Cafeara - PR apresentaram conflitos com calçamento e 13\% com a fiação, entretanto a baixa incidência de problemas deve-se a grande quantidade de indivíduos jovens, que ainda não estão causando danos aparentes. 
Sartori e Balderi (2011) relatam a mesma situação, afirmando que a espécie possui forte tendência a problemas futuros, por apresentar amplo crescimento e possuir raízes tabulares, desenvolvendo-se para os lados, inclusive com exposição para fora da terra, a fim de possibilitar uma melhor estabilidade à planta.

Nunes et al. (2013), constataram que $F$. benjamina foi a espécie que apresentou maiores conflitos com calçamento no bairro Ferraropólis na Cidade de Garça - SP, muito semelhante a situação registrada por Santana e Santos (1999) no que diz respeito ao conflito da espécie com o calçamento no câmpus da Universidade Estadual de Feira de Santana (UEFS). A espécie em questão ainda apresentou conflitos com equipamentos públicos em outros municípios, como Tuparendi - RS, onde foi possível verificar incompatibilidade com a rede de fiação elétrica presente no local (MOTTER e MULLER, 2012).

Outras espécies arbóreas registradas em Cafeara - PR, como $P$. aquática e $P$. pluviosa, também apresentaram incidência de conflitos juntos aos equipamentos públicos presentes na urbe, evidenciando o uso de espécies pouco compatíveis com o espaço disponível. No estudo elaborado por Nunes et al. (2013) é possível constatar que as duas espécies citadas desenvolveram conflitos com o calçamento e com a rede de fiação elétrica.

Em se tratando da $P$. pluviosa Sartori e Balderi (2011) denotam a ocorrência de danos a calçadas no município de Socorro - SP, comprometendo o acesso e a circulação de pedestres. No caso específico de Cafeara - PR, a espécie é responsável por cerca de $20 \%$ dos conflitos entre a arborização e os equipamentos públicos. Apesar dos conflitos observados Santos e Teixeira (2001) indicam a $P$. pluviosa para a arborização de vias públicas por apresentar crescimento rápido, rusticidade e características estéticas desejáveis.

Com o desenvolvimento do estudo foi observada a presença de 22 indivíduos de Mangifera indica L., espécie frutífera asiática. Para Santos e Teixeira (2001) o plantio desse tipo de espécie não é recomendado, pois os frutos desta podem causar acidentes a pedestres, sujeira, vandalismo e danos aos veículos.

Outra espécie frutífera encontrada no município foi Citrus limonia (L.) Osbeck (34 indivíduos), que possui acúleos, podendo ocasionar acidentes aos transeuntes. Além disso, esta espécie é elencada como exótica invasora no Paraná pela Portaria IAP 125/2009 (PARANÁ, 2009). Santos e Teixeira (2001), recomendam que a escolha de espécies com espinhos, acúleos e princípios alérgicos e/ou tóxicos deve ser evitada como indicado pela ABNT NBR 9050:2004 (ABNT, 2004). A ocorrência destas demonstra uma ação não planejada, feita provavelmente pela população, com a finalidade de alimentação. 
Tabela 2. Levantamento das espécies da arborização urbana do município de Cafeara Paraná

Tabela 2. Survey of urban tree species in the municipality of Cafeara - Paraná

\begin{tabular}{|c|c|c|c|c|c|c|c|c|c|c|c|c|}
\hline Família (Family) & Espécie (Species) & IND & $D_{M}$ & $\mathbf{Q}_{\mathrm{c}}$ & $\mathbf{A}_{\mathbf{c}}$ & $\mathbf{A}_{C T}$ & $\mathbf{Q}_{\mathrm{F}}$ & $A_{F}$ & $\mathbf{A}_{\mathrm{FT}}$ & $\mathbf{M}_{\mathbf{C}}$ & $M_{F}$ & $\overline{\mathbf{P}}$ \\
\hline \multirow{3}{*}{ Anarcadiaceae } & Mangifera indica L. & 22 & 1,1 & 0 & 0 & 0 & 4 & 18,1 & 2,9 & 1 & 2 & $\bar{E}$ \\
\hline & Schinus molle L. & 27 & 1,4 & 0 & 0 & 0 & 1 & 3,7 & 0,5 & 1 & 1 & $\mathrm{~N}$ \\
\hline & $\begin{array}{l}\text { Schinus terebinthifolius } \\
\text { Raddi. }\end{array}$ & 6 & 0,3 & 0 & 0 & 0 & 0 & 0 & 0 & 1 & 1 & $\mathrm{~N}$ \\
\hline Annonaceae & Annona squamosa L. & 2 & 0,1 & 0 & 0 & 0 & 0 & 0 & 0 & 1 & 1 & $\bar{E}$ \\
\hline \multirow{4}{*}{ Apocynaceae } & Nerium oleander L. & 11 & 0,5 & 0 & 0 & 0 & 0 & 0 & 0 & 1 & 1 & $\bar{E}$ \\
\hline & $\begin{array}{l}\text { Tabernaemontana } \\
\text { catharinensis A. DC. }\end{array}$ & 3 & 0,1 & 0 & 0 & 0 & 0 & 0 & 0 & 1 & 1 & $\mathrm{~N}$ \\
\hline & $\begin{array}{l}\text { Plumeria rubra L. } \\
\text { Thevetia }\end{array}$ & 2 & 0,1 & 0 & 0 & 0 & 0 & 0 & 0 & 1 & 1 & $\begin{array}{l}\mathrm{N} \\
\mathrm{E}\end{array}$ \\
\hline & $\begin{array}{l}\text { thevetioides (Kunth) } \\
\text { K.Schum }\end{array}$ & 1 & 0,1 & 0 & 0 & 0 & 0 & 0 & 0 & 1 & 1 & \\
\hline Araliaceae & $\begin{array}{l}\text { Schefflera arboricola } \\
\text { (Hayata) Merr. }\end{array}$ & 1 & 0,1 & 0 & 0 & 0 & 1 & 100 & 0,5 & 1 & 3 & $\bar{E}$ \\
\hline Arecaceae & $\begin{array}{l}\text { Dypsis lutescens (H. } \\
\text { Wendl.) Beentje \& J. } \\
\text { Dransf. }\end{array}$ & 33 & 1,7 & 0 & 0 & 0 & 0 & 0 & 0 & 1 & 1 & $E$ \\
\hline \multirow{3}{*}{ Bignoniaceae } & $\begin{array}{l}\text { Handroanthus albus } \\
\text { (Cham.) Mattos } \\
\text { Handroanthus }\end{array}$ & 20 & 1,0 & 0 & 0 & 0 & 0 & 0 & 0 & 1 & 1 & $\overline{\mathrm{N}}$ \\
\hline & $\begin{array}{l}\text { impetiginosus (Mart. } \\
\text { ex DC.) Mattos }\end{array}$ & 14 & 0,7 & 2 & 14,3 & 1,1 & 0 & 0 & 0 & 1 & 1 & \\
\hline & $\begin{array}{l}\text { Spathodea } \\
\text { campanulata Beauv. }\end{array}$ & 3 & 0,1 & 0 & 0 & 0 & 0 & 0 & 0 & 1 & 1 & $E$ \\
\hline Caricaceae & Carica papaya L. & 54 & 2,8 & 0 & 0 & 0 & 0 & 0 & 0 & 1 & 1 & $\bar{N}$ \\
\hline Chrysobalanaceae & $\begin{array}{l}\text { Licania tomentosa } \\
\text { (Benth.) Fritsch }\end{array}$ & 254 & 13,2 & 2 & 0,7 & 1,1 & 12 & 4,7 & 6,1 & 2 & 2 & $\bar{N}$ \\
\hline Combretaceae & Terminalia catappa L. & 29 & 1,5 & 2 & 6,9 & 1,1 & 12 & 41,3 & 6,1 & 2 & 3 & $\bar{E}$ \\
\hline Cupressaceae & $\begin{array}{l}\text { Cupressus } \\
\text { lusitanica Miller }\end{array}$ & 7 & 0,3 & 0 & 0 & 0 & 1 & 14,2 & 0,5 & 1 & 2 & $E$ \\
\hline Cycadaceae & $\begin{array}{l}\text { Cycas revoluta } \\
\text { Thunberg }\end{array}$ & 17 & 0,8 & 0 & 0 & 0 & 0 & 0 & 0 & 1 & 1 & $\bar{E}$ \\
\hline Euphorbiaceae & $\begin{array}{l}\text { Euphorbia } \\
\text { pulcherrima Willd ex } \\
\text { Koltz }\end{array}$ & 5 & 0,2 & 0 & 0 & 0 & 0 & 0 & 0 & 1 & 1 & $E$ \\
\hline \multirow{8}{*}{ Fabaceae } & Bauhinia forficata Link & 21 & 1,0 & 0 & 0 & 0 & 1 & 4,7 & 0,5 & 1 & 1 & $\overline{\mathrm{N}}$ \\
\hline & $\begin{array}{l}\text { Caesalpinia } \\
\text { pulcherrima (L.) Sw. }\end{array}$ & 5 & 0,2 & 0 & 0 & 0 & 2 & 40 & 1,0 & 1 & 1 & $E$ \\
\hline & $\begin{array}{l}\text { Cajanus cajan (L.) } \\
\text { Millsp. }\end{array}$ & 1 & 0,1 & 0 & 0 & 0 & 0 & 0 & 0 & 1 & 1 & $E$ \\
\hline & Cassia fistula L. & 1 & 0,1 & 0 & 0 & 0 & 0 & 0 & 0 & 1 & 1 & $E$ \\
\hline & $\begin{array}{l}\text { Delonix regia (Bojer ex } \\
\text { Hook) Raf. }\end{array}$ & 3 & 0,1 & 0 & 0 & 0 & 0 & 0 & 0 & 1 & 1 & $E$ \\
\hline & $\begin{array}{l}\text { Erythrina indica Lam } \\
\text { var. picta }\end{array}$ & 10 & 0,5 & 0 & 0 & 0 & 0 & 0 & 0 & 1 & 1 & $E$ \\
\hline & $\begin{array}{l}\text { Leucaena leucocephala } \\
\text { (Lam.) R. de Wit. }\end{array}$ & 10 & 0,5 & 0 & 0 & 0 & 0 & 0 & 0 & 1 & 1 & $E$ \\
\hline & $\begin{array}{l}\text { Poincianella pluviosa } \\
\text { var. peltophoroides } \\
\text { (Benth) L.P. Queiroz }\end{array}$ & 126 & 6,5 & 37 & 29,4 & 20,2 & 34 & 26,9 & 17,4 & 3 & 3 & $\mathrm{~N}$ \\
\hline
\end{tabular}


Tamarindus indica L.

\begin{tabular}{|c|c|c|c|c|c|c|c|c|c|c|c|c|}
\hline & Tamarindus indica L. & 1 & 0,0 & 0 & 0 & 0 & 0 & 0 & 0 & 1 & 1 & \\
\hline Lauraceae & Persea americana L. & 1 & 0,0 & 0 & 0 & 0 & 0 & 0 & 0 & 1 & 1 & - \\
\hline Lythraceae & $\begin{array}{l}\text { Lagerstroemia } \\
\text { indica (L.) Pers. }\end{array}$ & 2 & 0,1 & 0 & 0 & 0 & 0 & 0 & 0 & 1 & 1 & \\
\hline Magnoliaceae & $\begin{array}{l}\text { Magnolia champaca } \\
\text { (L.) Baill. ex Pierre }\end{array}$ & 7 & 0,3 & 0 & 0 & 0 & 0 & 0 & 0 & 1 & 1 & \\
\hline Malpighiaceae & Malpighia glabra L. & 5 & 0,2 & 0 & 0 & 0 & 0 & 0 & 0 & 1 & 1 & $\mathrm{E}$ \\
\hline \multirow{2}{*}{ Malvaceae } & $\begin{array}{l}\text { Hibiscus rosa-sinensis } \\
L \text {. }\end{array}$ & 18 & 0,9 & 0 & 0 & 0 & 0 & 0 & 0 & 1 & 1 & \\
\hline & Pachira aquatica Aublet & 236 & 12,3 & 39 & 16,5 & 21,3 & 53 & 22,4 & 27,1 & 2 & 3 & \\
\hline \multirow{2}{*}{ Melastomataceae } & $\begin{array}{l}\text { Tibouchina granulosa } \\
\text { (Ders.) Cogn. }\end{array}$ & 139 & 7,2 & 0 & 0 & 0 & 0 & 0 & 0 & 2 & 2 & \\
\hline & $\begin{array}{l}\text { Tibouchina sellowiana } \\
\text { (Cham.) Cogn. }\end{array}$ & 139 & 7,2 & 0 & 0 & 0 & 0 & 0 & 0 & 2 & 2 & \\
\hline Meliaceae & Melia azedarach L. & 9 & 0,4 & 0 & 0 & 0 & 1 & 11,1 & 0,5 & 1 & 2 & \\
\hline \multirow{3}{*}{ Moraceae } & $\begin{array}{l}\text { us } \\
\text { yllus Lam. }\end{array}$ & 2 & 0,1 & 0 & 0 & 0 & 1 & 50 & 0,5 & 1 & 3 & \\
\hline & jamina $\mathrm{L}$. & 527 & 27,5 & 101 & 19,2 & 55,2 & 68 & 12,9 & 34,8 & 4 & 4 & \\
\hline & Moru: & 4 & 0,2 & 0 & 0 & 0 & 0 & 0 & 0 & 1 & 1 & \\
\hline \multirow{4}{*}{ Myrtaceae } & $\begin{array}{l}\text { Callistemon viminallis } \\
\text { (Sol. ex Gaertn.) G. } \\
\text { Don. }\end{array}$ & 5 & 0,2 & 0 & 0 & 0 & 0 & 0 & 0 & 1 & 1 & \\
\hline & Eucalyptus sp. & 1 & 0,1 & 0 & 0 & 0 & 0 & 0 & 0 & 1 & 1 & \\
\hline & uniflora L. & 1 & 0,1 & 0 & 0 & 0 & 0 & 0 & 0 & 1 & 1 & \\
\hline & guajava L. & 19 & 0,9 & 0 & 0 & 0 & 0 & 0 & 0 & 1 & 1 & \\
\hline Oleaceae & $\begin{array}{l}\text { Ligustrum lucidum W. } \\
\text { T. Aiton }\end{array}$ & 28 & 1,4 & 5 & 17,9 & 2,73 & 2 & 7,1 & 1,0 & 2 & 2 & \\
\hline Papavera & Chelidonium majus L. & 1 & 0,1 & 0 & 0 & 0 & 0 & 0 & 0 & 1 & 1 & \\
\hline Protea & $\begin{array}{l}\text { Grevillea robusta A. } \\
\text { Cunn. }\end{array}$ & 1 & 0,1 & 0 & 0 & 0 & 1 & 100 & 0,5 & 1 & 3 & \\
\hline Punicaceae & Punica granatum L. & 1 & 0,1 & 0 & 0 & 0 & 0 & 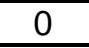 & 0 & 1 & 1 & $t$ \\
\hline Rosaceae & $\begin{array}{l}\text { Eriobotrya } \\
\text { japonica (Thunb.) Lindl. }\end{array}$ & 6 & 0,3 & 0 & 0 & 0 & 0 & 0 & 0 & 1 & 1 & \\
\hline $\mathrm{Rl}$ & Coffea arabica L. & 2 & 0,1 & 0 & 0 & 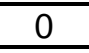 & 0 & 0 & 0 & 1 & 1 & E \\
\hline \multirow{2}{*}{ Rutaceae } & $\begin{array}{l}\text { Citrus limonia (L.) } \\
\text { Osbeck }\end{array}$ & 34 & 1,7 & 0 & 0 & 0 & 1 & 2,9 & 0,5 & 1 & 1 & \\
\hline & $\begin{array}{l}\text { Murraya paniculata (L.) } \\
\text { Jack. }\end{array}$ & 27 & 1,4 & 0 & 0 & 0 & 0 & 0 & 0 & 1 & 1 & \\
\hline Verbenaceae & Duranta erecta L. & 14 & 0,7 & 0 & 0 & 0 & 0 & 0 & 0 & 1 & 1 & $\mathrm{~N}$ \\
\hline
\end{tabular}

IND= Quantidade de indivíduos encontrados; $\mathbf{Q}_{\mathbf{F}}=$ Quantidade de indivíduos em conflito com a fiação; $\mathbf{A}_{\mathbf{F}}=$ Abundância de indivíduos da espécie em conflitos com a fiação; Aft= Abundância de indivíduos da espécie conflitantes com a fiação em relação ao total; $\mathbf{M}_{\mathbf{F}}=$ Relação entre abundância e indivíduos em conflito com a fiação; $\mathbf{Q}_{c}=$ Número de indivíduos em conflito com o calçamento; $\mathbf{A c}_{c}=$ Abundância de indivíduos da espécie em conflito com o calçamento; $\mathbf{A}_{c T}=$ Abundância de indivíduos da espécie conflitantes com o calçamento em relação ao total; $\mathbf{M}_{\mathbf{c}}=$ Relação entre abundância e indivíduos em conflito com o calçamento; $\mathbf{P}=$ Procedência; $\mathbf{N}=$ Nativa; E= Exótica;

Ao analisar a tabela disposta acima nota-se que a maioria das espécies apresenta baixos índices de conflitos entre a arborização e equipamentos públicos. Em geral, de cada 10 espécies encontradas 9 possuem índices de abundância inferiores a 5\% e, portanto, pouco interfere na representação dos conflitos registrados no município. 
A espécie que possui maior grau de relação entre abundância e conflitos é a $F$. benjamina, seguida das espécies: $P$. pluviosa, T. catappa e $P$. aquatica. Pelo grau de relação existente recomenda-se a realização de monitoramento e controle das espécies discutidas, a fim de evitar a continuidade dos conflitos presentes.

Com o propósito de caracterizar os conflitos da arborização com o calçamento e a fiação elétrica foi elaborado o croqui abaixo (Figura 2), visando demonstrar áreas com a maior incidência de interferências da arborização

Figura 2. Croqui das principais espécies em conflito com equipamentos públicos no município de Cafeara, Paraná

Figure 2. Sketch of the major species in conflict with public facilities in the city of Cafeara, Paraná

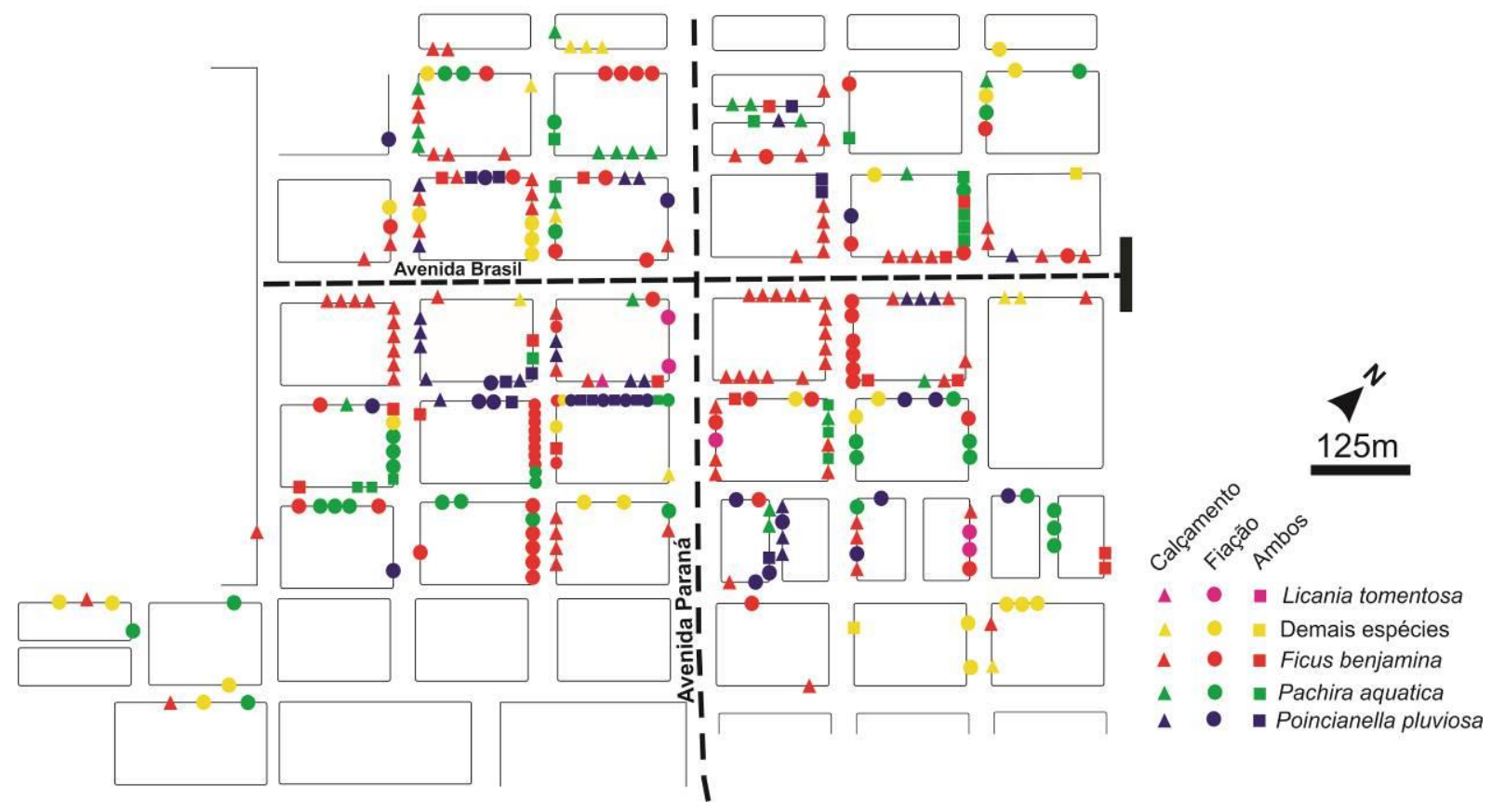

Em análise a figura 2 é possível comprovar novamente que a espécie mais conflitante foi a $F$. benjamina, sendo sozinha responsável por $55,2 \%$ dos conflitos entre a arborização e o calçamento urbano. As espécies $P$. aquatica e $P$. pluviosa apresentaram maior incidência de conflitos com a rede de fiação elétrica totalizando, respectivamente, 27,18 e $17,44 \%$ dos conflitos com a fiação. As demais espécies, apesar de juntas representarem aproximadamente $47 \%$ da composição arbórea do município, não registraram índices de conflitos tão significativos quanto às espécies mais abundantes.

Como forma de auxiliar na compreensão destes conflitos, a figura 3 aborda problemas encontrados na arborização urbana do município estudado, tais como: presença de raízes expostas (danificando o calçamento e obstruindo a passagem de pedestres), 
existência de galhos em conflitos com a fiação, manejo com prática de podas drásticas, necessidade de destoca, além de indivíduos jovens plantados em área inferior a $1 \mathrm{~m}^{2}$, configurando segundo a ABNT NBR 9050:2004 (ABNT, 2004) possíveis danos futuros ao calçamento.

Figura 3. Espécimes arbóreos em conflitos com equipamentos públicos do município de Cafeara - Paraná

Figure 3. Arboreal specimens in conflict with public facilities in the municipality of Cafeara Paraná

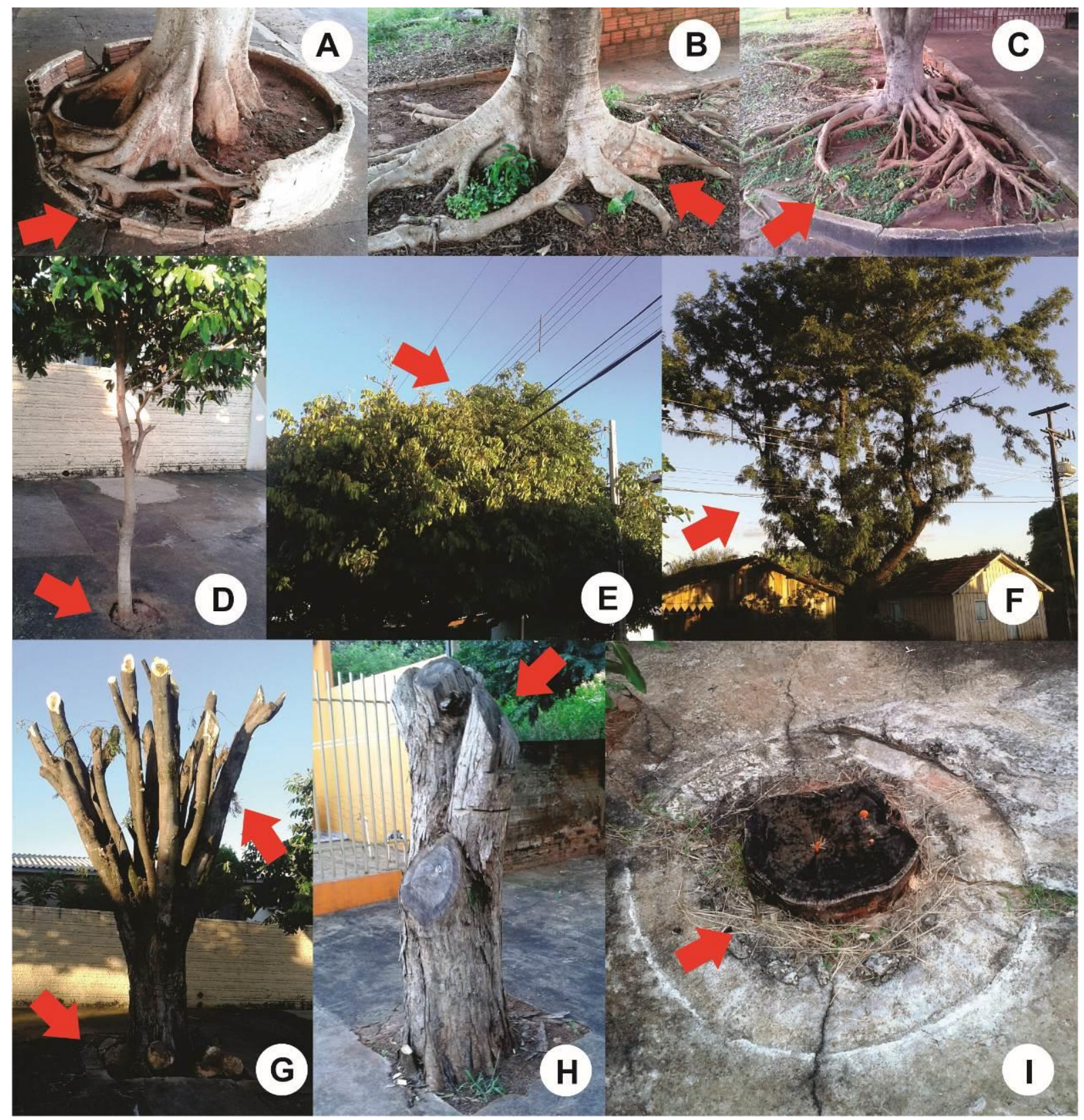

A-C. Raízes expostas; D. Espécime plantado em área inferior ao recomendado; E-F. Galhos em contato direto com a fiação elétrica; G-H. Realização de poda drástica, ocasionando na supressão total dos galhos; I. Corte do espécime vegetal, sem a realização do processo de destocagem. 
A prática da arborização no município vem sendo comprometida pela falta de manejo e inexistência de uma política eficaz que garanta plantio adequado e manutenção dos espécimes cultivados. Além disso, muitas espécies em desenvolvimento na área de estudo não se enquadram nos critérios que devem ser seguidos para o planejamento da arborização urbana, definidos como: ausência de espinhos, acúleos, princípios alergênicos e/ou tóxicos, resistência a pragas e doenças, crescimento rápido, ausência de frutos grandes e porte adequado ao espaço disponível (SANTOS; TEIXEIRA, 2001).

Desta forma, deve-se analisar os aspectos acima elencados, para, deste modo, diminuir o surgimento de transtornos futuros e a ocorrência de conflitos com equipamentos públicos e privados, reduzindo ainda custos com manutenção e garantindo qualidade de vida aos moradores locais.

\section{CONCLUSÕES}

Por todo exposto, verifica-se o predomínio de espécies exóticas na composição arbórea da área de estudo. Quanto à abundância é possível observar a maior ocorrência de três espécies ( $F$. benjamina, L. tomentosa e $P$. aquatica), sendo estas responsáveis por $53 \%$ dos espécimes arbóreos encontrados em Cafeara - PR.

Em relação aos conflitos da arborização com equipamentos públicos (calçamento e rede de fiação elétrica) nota-se maior concentração de problemas na porção central da cidade. A espécie que registrou maior grau de conflitos na urbe foi a $F$. benjamina que, pela análise entre abundância e ocorrência de conflitos, necessita da realização de controle imediato.

De forma geral, percebe-se que apesar dos benefícios associados à arborização a cidade amarga prejuízos com a falta de planejamento no setor, acarretando, por vezes, maiores custos com manutenção, transtornos para a população e conflitos desnecessários com equipamentos públicos existentes. 


\section{REFERÊNCIAS}

ABNT. ASSOCIAÇÃO BRASILEIRA DE NORMAS TÉCNICAS. NBR 9050:2004. Acessibilidade a edificações, mobiliário, espaços e equipamentos urbanos. 2004

AMIR, S.; MISGAV, A. A Framework for Street Tree Planing in Urban areas in Israel. Landscape and urban Planning Amsterdam: Elsevier, 1990.

ANDREATTA, T. R.; BACKES, F. A. A. L.; BELLÉ, R. A.; NEUHAUS, M.; GIRARDI, L. B.; SCHWAB, N. T.; BRANDÃO, B. S. Análise da arborização no contexto urbano de avenidas de Santa Maria, RS. Revista da Sociedade Brasileira de Arborização Urbana, v. 6, n. 1, p.36-50, 2011.

APG III. An update of the Angiosperm Phylogeny Group classification for the orders and families of flowering plants: APG III. Botanical Journal of the Linnean Society, London, v. 16, p. 105-121, 2009.

ARAUJO, M. N.; ARAUJO, A. J. Arborização Urbana. Série de Cadernos Técnicos. CREAPR. 2011.

BIONDI, D.; ALTHAUS, M. Árvores de Rua de Curitiba: Cultivo e Manejo. Curitiba: FUPEF, 1. ed. 117p., 2005.

BIONDI, D.; MACEDO, J. H. P. Plantas invasoras encontradas na área urbana de Curitiba (PR). Revista Floresta. v. 38, n. 1. 2008.

FIDALGO, O.; BONONI, V. L. R. Técnica de coleta, preservação e herborização de material botânico. São Paulo: Série Documentos. 62p., 1989.

GUZZO, P. Programa Pró-Ciências: Arborização Urbana. 2008. Disponível em: <http://educar.sc.usp.br/biologia/prociencias/arboriz.html>. Acesso em: 21 mar. 2013.

IAPAR - INSTITUTO AGRONÔMICO DO PARANÁ. Cartas Climáticas do Paraná. Disponível em <http://www.iapar.pr.gov.br/modules/conteudo/conteudo.php?conteudo=677> Acesso em: 10 dez. 2012.

IBGE. INSTITUTO BRASILEIRO DE GEOGRAFIA E ESTATÍSTICA. 2010a. Censo Demográfico. Disponível em: <http://saladeimprensa.ibge.gov.br/noticias?view=noticia\&id $=1 \&$ busca $=1$ \&idnoticia=1766> . Acesso em: 24 fev .2013. 
IBGE. INSTITUTO BRASILEIRO DE GEOGRAFIA E ESTATÍSTICA. 2010b. Censo Demográfico. Disponível em: <http://www.ibge.gov.br/home/estatistica/populacao/censo 2010/default.shtm>. Acesso em: 24 fev. 2013.

IBGE. INSTITUTO BRASILEIRO DE GEOGRAFIA E ESTATÍSTICA. Manual técnico da vegetação brasileira: sistema fitogeográfico, inventário das formações florestais e campestres, técnicas e manejo de coleções botânicas, procedimentos para mapeamentos. Rio de janeiro: IBGE- Diretoria de Geociências, 2012. 271p. (Manuais Técnicos de Geociências, 1).

ITCG. INSTITUTO DE TERRAS, CARTOGRAFIA E GEOCIÊNCIAS. Dados Geoespaciais de referência. 2014. Disponível em:<http://www.itcg.pr.gov.br/modules/faq/category.php? categoryid=8\#>. Acesso em: 07 set 2012.

IPNI. The International Plant Name Index, 2013. Disponível em: <http://www.ipni.org/>. Acesso em: 25 abr. 2013.

KOPPEN, W. 1931. Grundriss der Klimakunde. Walter de Gruyter Co., Berlin. 388p

Lista de Espécies da Flora do Brasil, 2013. Disponível em: <http://floradobrasil.jbrj.gov.br/>. Acesso em: 30 de abr. 2013.

LORENZI, H. Árvores Brasileiras: manual de identificação e cultivo de arbóreas nativas do Brasil, v.1, n. 4 Ed. Nova Odessa: Instituto Plantarum. 2002. 384 p.

LORENZI, H.; SOUZA, H. M.; TORRES, M. A. V.; BACHER, L. B. Árvores exóticas no Brasil: madeiras, ornamentais e aromáticas. Nova Odessa: Instituto Plantarum, v.1. 2003, 368p.

MARANHO, Á. S; PAULA, S. R. P. de; PAIVA, A. V. de; ALVES, A. P; NASCIMENTO, D. O. de. Levantamento censitário da arborização urbana viária de Senador Guiomard, Acre. Revista da Sociedade Brasileira de Arborização Urbana, v. 7, n. 3, p. 44-56, 2012.

MAY, R. M. Patterns of species abundance and diversity. In: Ecology and Evolution of communities, Cody, M. L. \& Diamond, J. M. (eds). Cambridge: Belknap Press, Harvard University, p. 81-120, 1975

MEIRELLES, H. L. Direito Municipal Brasileiro. São Paulo: RT, 1977, 3 ed., 89 p.

MELLO FILHO, L. E. Arborização urbana. In: ENCONTRO NACIONAL SOBREARBORIZAÇÃO URBANA, 1, Porto Alegre, 1985. Anais... Porto Alegre. p.117-127. 1985. 
MILANO, M. S.; DALCIN, E. C. Arborização de vias públicas. Rio de Janeiro: Light, 2000. 226p.

MOSER, P.; DA SILVA, A. C.; HIGUCHI, P.; DOS SANTOS, E. M.; SCHMITZ, V. Avaliação pós-tempestade da Arborização do Campus da Universidade do Estado de Santa Catarina, Lages-SC. Revista da Sociedade Brasileira de Arborização Urbana, v.5, n.2, p.40-51, 2010.

MOTTER, N.; MÜLLER, N. G. Diagnóstico da arborização urbana no município de Tuparendi-RS. Revista da Sociedade Brasileira de Arborização Urbana, v.7, n.4, p.27-36, 2012.

MOURA, T. A.; SANTOS, L. V. Levantamento quali-quantitativo de espécies arbóreas e arbustivas na arborização viária urbana dos Bairros Centro e Centro Norte, Várzea Grande, Mato Grosso, Brasil. Revista da Sociedade Brasileira de Arborização Urbana, v.1, n.1, p.97-117, 2009.

NUNES, R. L.; MARMONTEL, C. V. F.; RODRIGUES, J. P.; MELO, A. G. C.; Levantamento qualiquantitativo da arborização urbana do bairro Ferraropólis na cidade de Garça-SP. Revista da Sociedade Brasileira de Arborização Urbana, v.8, n.1, p. 65-74, 2013.

OLIVEIRA, R. F. De urbis arboreto: o espaço primitivo interpretado. In SEMINÁRIO DE ARBORIZAÇÃO URBANA NO RIO DE JANEIRO, 1., 1996, Rio de Janeiro. Anais ...Rio de Janeiro:UFRJ, 1996. p $33-44$.

PAIVA, A. V. Aspectos da arborização urbana do centro de Cosmópolis-SP. Revista da Sociedade Brasileira de Arborização Urbana, v. 4, n. 4, p. 17-31, dez. 2009.

PARANÁ. Lei Estadual n 15.953, de 24 de setembro de 2008. Proíbe o plantio, comércio, transporte e produção da planta Murta (Murraya paniculata), por ser vegetal hospedeiro da bactéria Candidatus liberibacter ssp., disseminada pelo inseto vetor Diaphorina citri, transmissor da praga denominada Huanglongbing (HLB - Greening). Diário Oficial do Estado do Paraná, Curitiba, PR, 08 out. 2008.

PARANÁ. Portaria № 125, de 07 de agosto de 2009. Reconhece a lista oficial de espécies exóticas invasoras para o estado do Paraná, estabelece normas de controle e dá outras providências. Diário Oficial do Estado do Paraná, Curitiba, PR, 07 set. 2009.

PELEGRIM, E. A. P.; LIMA, A. P. L. de; LIMA, S. F. de. Avaliação qualitativa e quantitativa da arborização no bairro Flamboyant em Chapadão do Sul, MS. Revista da Sociedade Brasileira de Arborização Urbana, v. 7, n. 1, p. 126-142, 2012.

PIRES, R. K.; DIAS, M. B.; BRITO, J. O conflito: arborização X energia elétrica, no bairro Vermelha, em Teresina-PI. In: CONGRESSO DE PESQUISA E INOVAÇÃO DA REDE 
NORTENORDESTE DE EDUCAÇÃO TECNOLÓGICA. 2. Anais... João Pessoa - Paraíba, 2007. $08 \mathrm{p}$.

PIVETTA, K. F. L.; SILVA FILHO, D. F. Arborização urbana. Jaboticabal: Boletim Acadêmico (Série Arborização Urbana). UNESP/FCAV/FUNEP, 2002. 74p.

PREISSLER, A. A. Arborização Urbana Pública: Benefícios e problemas ambientais. 2011. Disponível em: <http://arborizacaoplantasmultifuncionais.blogspot.com.br/2011/06/ arborizacao-urbana-publica-beneficios-e.html> Acesso em: 21 jan. 2013.

RODERJAN, C. V, GALVÃO, F., KUNIYOSHI, Y. S.; HATSCHBACH, G. G. As unidades fitogeográficas do Estado do Paraná, Brasil. Revista Ciência \& Ambiente, v .1, n.24, jan. jun., p.75-92, 2002.

SAMPAIO, A. C. F.; DE ANGELIS, B. L. D. Inventário e análise da arborização de vias públicas de Maringá - PR. Revista da Sociedade Brasileira de Arborização Urbana. v. 3, n.1, p. 37-57, 2006.

SANTANA, J. R. F.; SANTOS, G. M. M. Arborização do campus da UEFS: exemplo a ser seguido ou um grande equívoco? Sitientibus, n.20, p.103-107, 1999.

SANTOS, N. R. Z; TEIXEIRA, I. F. Arborização de Vias Públicas: Ambiente X Vegetação, Porto Alegre: Editora Pallotti, 2001,135 p.

SARTORI, R. A.; BALDERI, A. P. Inventário da arborização urbana do município de Socorro- SP e proposta de um índice de danos à infra-infraestrutura das cidades. Revista da Sociedade Brasileira de Arborização Urbana, v.6, n.4, p.68-89, 2011.

SEITZ, R. A. Manual: A Poda de Árvores Urbanas. Piracicaba, 1996, 27p.

ZILLER, S. R. Espécies exóticas invasoras em Unidades de Conservação. In: CONGRESSO BRASILEIRO DE UNIDADES DE CONSERVAÇÃO. 4. Anais... 2004.

WBCSD. Measuring Impact: Framework Methodology. Arlington: AES Corporation, 2008, v.1, 78p. 